\title{
Avaliação do escoamento superficial de água de chuva em um fragmento de Mata Atlântica no município de Viçosa, MG
}

\author{
Paulo Saraiva Neto ${ }^{1}$ \\ Vanessa Pataro Maffia ${ }^{1}$ \\ Herly Carlos Teixeira Dias ${ }^{1}$ \\ Wellington Avelar de Souza e Silva ${ }^{1}$ \\ ${ }^{1}$ Universidade Federal de Viçosa - UFV \\ Avenida Peter Henry Rolfs, s/n, Campus Universitário - 36570-000 -Viçosa - MG, Brasil \\ paulonarg@ig.com.br \\ vpmaffia@yahoo.com.br \\ herly@ufv.br \\ tomavelar@hotmail.com
}

\begin{abstract}
The human practices affect water resources directly. The vegetation impedes the action of pluvial waters, when it's reducing the soil impact and the superficial drainage speed. Several studies have been developed with intention to explain and to quantify the relationship between the kind of covering vegetable and the superficial drainage process. This way, the present work had a aim at to measure and install plots to monitoring and evaluation of the drainage superficial located at Atlantic Forest in Viçosa, MG. The collection of data was accomplished during the months of May and June of 2009, starting from isolated rain events. The percentage of the superficial drainage in relation to the precipitation it was very low, or even null, depending on the intensity of the rain event. The results suggest that the superficial drainage is influenced by countless factors of the vegetation, could vary strongly even in neighboring areas, with similar characteristics.
\end{abstract}

Palavras-chave: escoamento superficial, precipitação efetiva, monitoramento hidrológico, mata nativa.

\section{Introdução}

$\mathrm{O}$ uso indiscriminado dos recursos naturais tem sido um dos temas mais discutidos e comentados em todo o planeta. O grande impacto causado pelo homem está refletido no desequilíbrio de vários ecossistemas, além da escassez de recursos para uma grande parcela da população. Podemos constatar esta situação tanto em âmbito mundial quanto em âmbito regional. Na Zona da Mata Mineira são vários os relatos de áreas repletas de voçorocas, rios assoreados, enchentes, secas, deslizamentos de terra, estradas destruídas devido à erosão, cursos de água e lençóis freáticos poluídos. Está claro que o desencadeamento destes processos está ligado à devastação do ecossistema em questão, para fins agropecuários e urbanos.

As diversas práticas humanas afetam os recursos hídricos diretamente. Quando a vegetação nativa é removida, o comportamento hidrológico da bacia hidrográfica muda fortemente. O tipo de cobertura vegetal influencia diretamente os processos do ciclo hidrológico como, por exemplo, a infiltração e o escoamento superficial. Quando estes processos são alterados, há uma mudança na regulação da vazão dos rios, já que a recarga do lençol freático não ocorre adequadamente. Se a infiltração da água no solo é prejudicada, o escoamento superficial aumenta consideravelmente, ocasionando erosão, assoreamento dos cursos d'água e enchentes.

Microbacias podem apresentar contribuições hidrológicas distintas mesmo apresentando superfícies similares, havendo portanto vários fatores envolvidos na dinâmica e na administração da água (COELHO, 2001). A cobertura vegetal, situação topográfica, exposição às massas de ar, geologia, tipos e características dos solos, níveis de antropização e fatores morfométricos são alguns relacionados na literatura como determinantes (UFRRJ, 
1987). Alterações de apenas alguns destes fatores podem acarretar mudanças de comportamento hidrológico, influindo na regulação da vazão dos rios e principalmente nas de bacias de $1^{\circ}$ ordem da mata atlântica (FARIA, 1996).

A vegetação tem papel importante na estabilidade do solo. O manto florístico amortece o impacto das chuvas, regularizando e reduzindo o escoamento superficial e aumentando o tempo disponível para absorção da água pelo subsolo. A vegetação impede, assim, a ação direta das águas pluviais sobre o manto de alteração, reduzindo o impacto no solo, e a velocidade do escoamento superficial, contribuindo para evitar a instalação de processos de instabilidade. A deposição de material orgânico, a serrapilheira, possui grande eficácia na redução dos danos causados pela ação erosiva das gotas de chuva, colaborando ainda para a capacidade de infiltração, estando sua produção intimamente ligada às condições da vegetação.

A erosão hídrica é um processo físico de desagregação, transporte e deposição de partículas do solo, provocado pela ação da água das chuvas e do escoamento superficial. Os solos também possuem um papel muito importante dentro do ciclo ecológico, pois atuam como reservatório natural de águas e também como agente regulador do escoamento superficial e sub-superficial (COELHO NETTO, 1994).

Pesquisas voltadas para a medição dos processos hidrológicos em bacias de drenagem, embora de grande utilidade para o gerenciamento dos recursos hídricos, ainda são escassas no Brasil. A maioria dos estudos é proveniente de países desenvolvidos, notadamente Estados Unidos e Inglaterra. As primeiras pesquisas em bacias de drenagem começaram com a criação do Serviço de Conservação do Solo dos Estados Unidos, no final da década de 30. Ressalta-se ainda que nos anos 30 surgiram os resultados dos trabalhos de Horton (1933) que marcaram profundamente o desenvolvimento da pesquisa hidrológica (ARAÚJO NETO, 1994).

Vários estudos vêm sendo desenvolvidos no intuito de esclarecer e quantificar a relação entre o tipo de cobertura vegetal e o processo de escoamento superficial. No entanto, as bacias hidrográficas e seus atributos físicos, biológicos e climáticos podem assumir características muito distintas. Portanto, a elaboração de diferentes metodologias para se avaliar o escoamento superficial se faz necessária.

Sendo assim, o presente trabalho teve como objetivo dimensionar e instalar parcelas para o monitoramento e avaliação do escoamento superficial de água de chuva num fragmento de Mata Atlântica localizado no município de Viçosa, MG.

\section{Metodologia}

\section{Localização e caracterização da área}

A Mata do Paraíso, um fragmento de Mata Atlântica, localiza-se em Viçosa, na Zona da Mata de Minas Gerais, a $229 \mathrm{~km}$ da capital Belo Horizonte. Situado entre as latitudes de

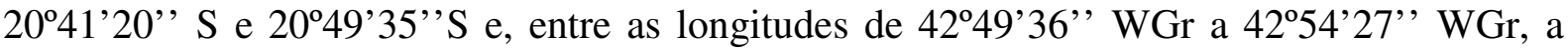
uma altitude média de 650 metros, o município abrange uma área de $300,15 \mathrm{~km}^{2}$. A Mata do Paraíso situa-se a aproximadamente $6 \mathrm{~km}$ da Universidade Federal de Viçosa e possui uma área de 194 hectares.

A área de estudo está inserida no Centro de Pesquisas Mata do Paraíso e se encontra em processo de regeneração natural, ainda num estágio sucessional inicial. Foram instaladas três parcelas para avaliação e monitoramento do escoamento superficial. Estão situadas na coordenada UTM 23K 0723423, 7697874.

As declividades das parcelas 1, 2 e 3 são, respectivamente de $29 \%, 25 \%$ e $15 \%$. 


\subsection{Instalação e monitoramento das parcelas}

Optou-se por um dimensionamento condizente com as características da área, sendo este de 3x5metros. Porém, após a instalação as dimensões reais das parcelas foram se adequando de acordo com as particularidades do local do experimento. Portanto, a parcela 1 tem 13,71 $\mathrm{m}^{2}$ (FIGURA 1), a parcela 2 tem 14,79 $\mathrm{m}^{2}$ (FIGURA 2) e a parcela 3 tem 14,86 $\mathrm{m}^{2}$ (FIGURA $3)$.

A parte inferior de cada parcela é dotada de uma calha, na qual foi coletada a água escoada, sendo armazenada em galões conectados.

Para delimitar as parcelas foram utilizadas chapas de ferro galvanizado. A calha para coleta da água tem a mesma constituição. Para conectar a calha aos galões, optou-se pela utilização de tubulações e fez-se necessário o uso de conectores do tipo "joelho". Para a vedação entre as chapas de ferro, utilizou-se um adesivo chamado de veda-calha.

A primeira etapa da instalação foi a abertura de sulcos para acomodar as chapas de ferro e as calhas. Após a instalação das placas, pequenas covas foram feitas ao lado das parcelas para abrigar os galões de coleta.

A inclinação da calha foi feita criteriosamente, com o auxílio de um medidor de nível, de modo a garantir que a água de chuva captada se dirija para a saída conectada ao galão.

O monitoramento e avaliação do escoamento superficial foram realizados durante os meses de maio e junho de 2009, a partir de eventos de chuva isolados. Os dados obtidos foram relacionados à precipitação efetiva e em aberto, quantificando-se a porcentagem da água de chuva que se converteu em escoamento superficial.

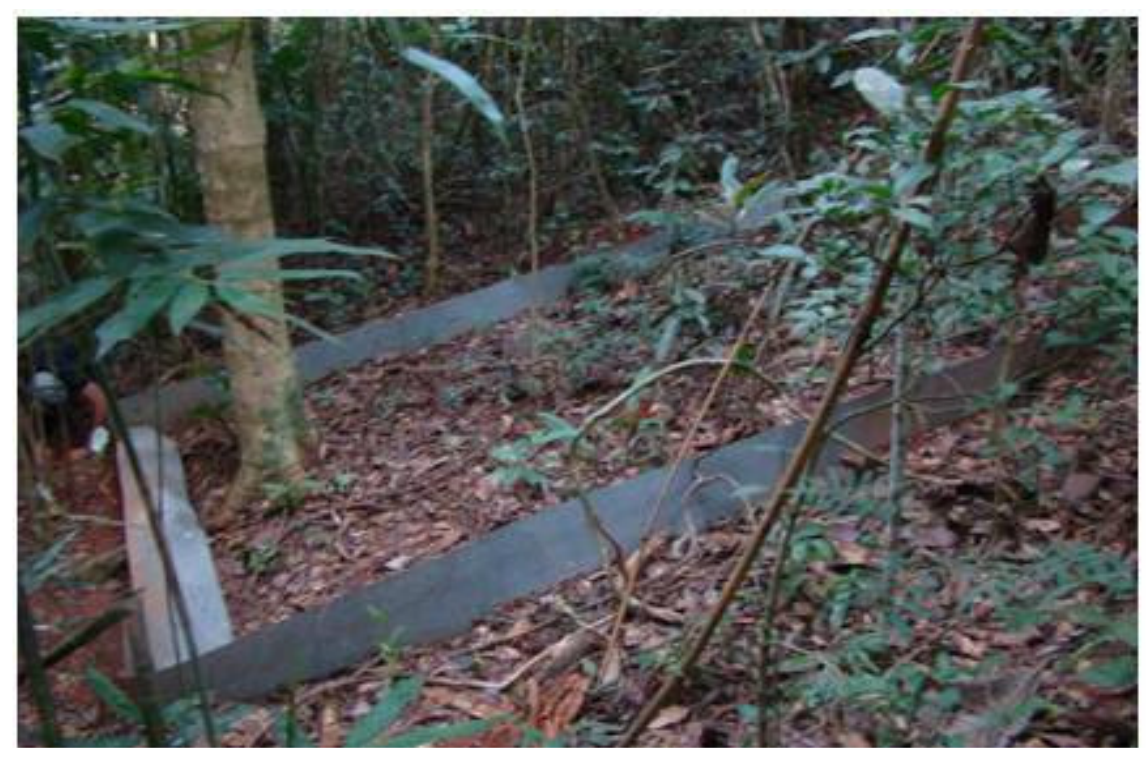

Figura 1 - Parcela (1) para avaliação do escoamento superficial na Mata do Paraíso, Viçosa - MG. 


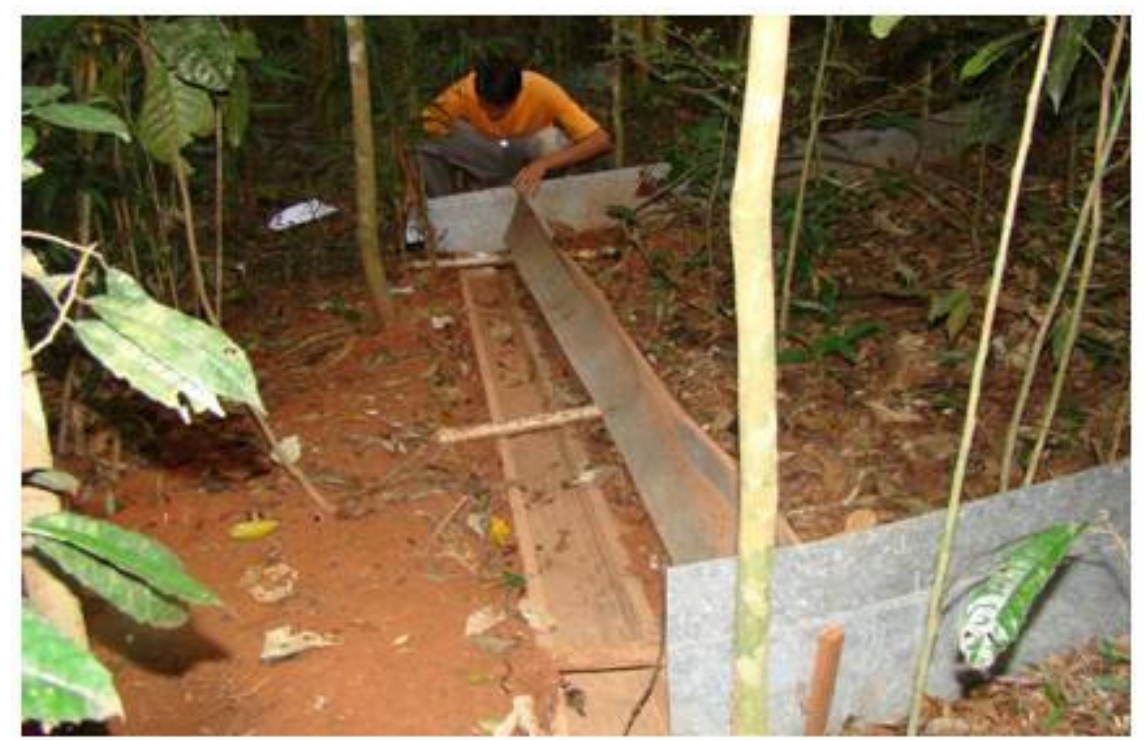

Figura 2- Parcela (2) para avaliação do escoamento superficial na Mata do Paraíso, Viçosa - MG.

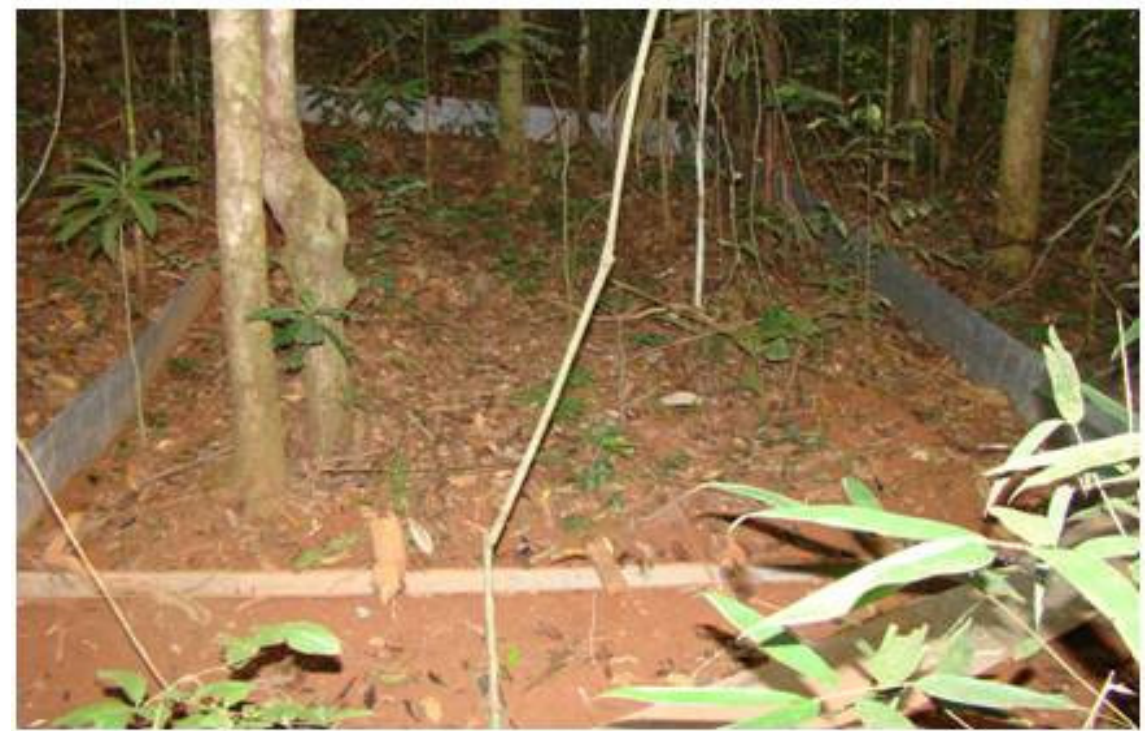

Figura 3- Parcela (3) para avaliação do escoamento superficial na Mata do Paraíso, Viçosa - MG.

\subsection{Precipitação total e efetiva}

Para se realizar a quantificação da precipitação em aberto, ou total, utilizou-se dados de um pluviômetro localizado no local do experimento, sendo este instalado em local aberto, livre de barreiras para a captação da precipitação. Este pluviômetro possuí uma área seccional, na abertura pela qual a água é coletada, de $167,42 \mathrm{~cm}^{2}$. Utilizou-se complementarmente, dados obtidos de um pluviógrafo localizado nas proximidades da Mata do Paraíso, também isento de impedimentos para a captação da chuva. Foram obtidos dados de eventos de chuva isolados durante o mês de maio e junho.

A precipitação efetiva é a soma da precipitação interna e do escoamento pelo tronco. Para a quantificação da precipitação interna foram utilizados os dados obtidos de uma parcela de $400 \mathrm{~m}^{2}$ com 25 pluviômetros dispostos num espaçamento de 5x5metros, localizados ao lado 
das parcelas de escoamento superficial. A área seccional na abertura destes pluviômetros é de $77 \mathrm{~cm}^{2}$. O escoamento pelo tronco foi obtido através de calhas instaladas nas árvores com DAP igual ou superior a $10 \mathrm{~cm}$, numa subparcela de $100 \mathrm{~m}^{2}$, entre os pluviômetros.

6. Sugestões para minimizar o tamanho das figuras

\section{Resultados e discussão}

A instalação de parcelas para monitoramento e avaliação do escoamento superficial sob vegetação nativa, em especial a Mata Atlântica, deve levar em conta as peculiaridades do bioma. A quantidade de raízes presentes no solo, a declividade, o estágio sucessional e as dificuldades de acesso à área são alguns dos fatores de maior relevância. Portanto, o material utilizado se adequou às condições locais, sendo flexível e resistente, permitindo o contorno dos obstáculos existentes, como as já mencionadas raízes e os troncos das árvores.

A avaliação do escoamento superficial foi realizada a partir de eventos de chuva isolados, no mês de maio e junho de 2009 (Tabela 1).

Tabela 1 - Precipitação e escoamento superficial na Mata do Paraíso, maio a junho de 2009, Viçosa-MG.

\begin{tabular}{|c|c|c|c|c|c|c|c|c|c|c|c|}
\hline \multirow[t]{2}{*}{ Data } & \multirow[t]{2}{*}{ Parcela } & \multirow[t]{2}{*}{ PA } & \multicolumn{2}{|c|}{ Pe } & \multicolumn{2}{|c|}{$\mathbf{P i}$} & \multicolumn{2}{|c|}{ Etr } & \multicolumn{3}{|c|}{ Esup } \\
\hline & & & $\mathbf{m m}$ & $\%$ & $\mathbf{m m}$ & $\%$ & $\mathbf{m m}$ & $\%$ & $\mathbf{m m}$ & $\% \mathbf{P A}$ & $\% \mathrm{Pe}$ \\
\hline \multirow[t]{3}{*}{ 03/05/09 } & 1 & 7,0 & 5,14 & 73,46 & 5,11 & 73 & 0,032 & 0,46 & 0 & 0 & 0 \\
\hline & 2 & & & & & & & & 0 & 0 & 0 \\
\hline & 3 & & & & & & & & 0 & 0 & 0 \\
\hline Média & & & & & & & & & 0 & 0 & 0 \\
\hline \multirow[t]{3}{*}{$11 / 05 / 09$} & 1 & 20,9 & 12,01 & 57,46 & 11,97 & 57,27 & 0,039 & 0,2 & 0,0091 & 0,04 & 0,08 \\
\hline & 2 & & & & & & & & 0,0473 & 0,23 & 0,39 \\
\hline & 3 & & & & & & & & 0,0037 & 0,02 & 0,03 \\
\hline Média & & & & & & & & & 0,020 & 0,10 & 0,17 \\
\hline \multirow[t]{3}{*}{$10 / 06 / 09$} & 1 & 8,5 & 2,19 & 25,75 & 2,18 & 25,64 & 0,009 & 0,11 & 0,0083 & 0,03 & 0,10 \\
\hline & 2 & & & & & & & & 0,0195 & 0,23 & 0,89 \\
\hline & 3 & & & & & & & & 0,0022 & 0,10 & 0,38 \\
\hline Média & & & & & & & & & 0,0010 & 0,12 & 0,46 \\
\hline \multirow[t]{3}{*}{ 17/06/09 } & 1 & 21,5 & 17,751 & 82,5 & 17,532 & 81,5 & 0,219 & 1,0 & 0,0056 & 0,03 & 0,03 \\
\hline & 2 & & & & & & & & 0,0751 & 0,35 & 0,42 \\
\hline & 3 & & & & & & & & 0,0022 & 0,01 & 0,01 \\
\hline Média & & & & & & & & & 0,0276 & 0,13 & 0,16 \\
\hline
\end{tabular}


A declividade média da área é de $23 \%$, sendo esta informação imprescindível para se avaliar o escoamento superficial. $\mathrm{O}$ aumento da inclinação do terreno influencia positivamente na taxa de escoamento superficial. As parcelas 1 e 2, com declividade de 29 e $25 \%$, respectivamente, apresentaram taxas mais elevadas em relação à parcela 3 , com declividade de $15 \%$.

Para uma precipitação total de 7,0 mm, o escoamento superficial não foi desencadeado. A precipitação efetiva correspondeu a 73,46\% deste evento de chuva, indicando que o restante da água se infiltrou ou foi interceptada pela vegetação local. Este resultado demonstra que provavelmente o escoamento superficial se inicia apenas a partir de uma intensidade e quantidade de precipitação que exceda a capacidade de interceptação da cobertura vegetal e a capacidade de infiltração da água no solo.

Para uma precipitação total de $20,9 \mathrm{~mm}$, apenas $0,10 \%$ escoou superficialmente. A precipitação efetiva representa $57,46 \%$ da total, sendo que deste valor o escoamento superficial representa $0,17 \%$.

\section{Conclusão}

Após o término da instalação das parcelas e feitas as coletas, nota-se a dificuldade em elaborar uma metodologia eficiente. Para que a água do escoamento superficial seja captada em sua totalidade é necessária uma manutenção constante, para que as parcelas permaneçam íntegras, assegurando assim que toda a água chegue até os galões de armazenamento. A cada evento de chuva, há perda de partículas do solo, principalmente próximo à calha, o que pode afetar a captação da água escoada.

Os resultados sugerem que o escoamento superficial seja influenciado por inúmeros fatores, podendo variar fortemente mesmo em áreas vizinhas, com características similares.

A porcentagem do escoamento superficial em relação à precipitação efetiva e em aberto foi muito baixa, ou mesmo nula, dependendo da intensidade do evento de chuva, sugerindo a influência da cobertura vegetal no desencadeamento deste processo.

A água coletada provinda do escoamento superficial apresentou aparente turbidez elevada, após avaliação visual. Provavelmente devido à grande quantidade de sedimentos e nutrientes que podem ser arrastados neste processo.

superficial representa $0,17 \%$.

\section{Agradecimento}

Os autores agradecem à Fundação de Apóio a Pesquisa do Estado de Minas Gerais, FAPEMIG, por financiar a participação no SERHIDRO.

\section{Referências}

ARAÚJO NETO, M. D., 1994. Métodos de medição da água no solo: Uma breve discussão. Geonomos, 2 , (2): p. 51-61.

COELHO NETTO, A. L., 1994. Hidrologia de encosta na interface com a geomorfologia. Geomorfologia: uma atualização de bases e conceitos. p. 93-148.

COELHO, G. Considerações sobre o manejo hidrológico da Mata Atlântica, 101 p, 2001 (dissertação de mestrado) UFRRJ.

FARIA, A.P. Dinâmica das bacias fluviais de primeira ordem. Tese de doutorado. Rio de Janeiro: UFRRJ.1996. 215p.

Horton, R.E. 1933. The role of infiltration in the hydrologic cycle. American Geophysical Union Transaction, Washington, v.14, p.446-460. 
Anais II Seminário de Recursos Hídricos da Bacia Hidrográfica do Paraíba do Sul: Recuperação de Áreas Degradadas, Serviços Ambientais e Sustentabilidade, Taubaté, Brasil, 09-11 dezembro 2009, IPABHi, p. 133-140.

(doi:10.4136/serhidro.18)

UFRRJ. Diagnóstico ambiental das bacias dos rios Quimbira e Marimbondo. Relatório final, UFRRF/FINAMA. 1993. 63p. mapas. 